\title{
Cezalandırma Konusunda Faydacı Teori Ve Kefaret Teorisinin Karşılaştırılması
}

\begin{abstract}
Burcu ENIS ${ }^{1}$
Özet

Bu çalışmada toplum düzenini bozan davranışlara karşı sosyal tepki ifadesi taşıyan cezanın gerekliliği ve zorunluluğu üzerinde durulmuştur. Hukuksal sistemde ise bu davranışın ismi suç olarak karşımıza çıkmıştır. Öncelikle cezalandırmanın amacı belirlenmeye çalışılmış ve cezalandırma söz konusu olduğunda kabul gören teorilerin ikisinden söz edilmiştir. Bu teorilerden biri olan kefaret teorisinde cezanın kendisi bir amaç olarak görülürken diğer bir teori olan faydacı teoride ise ceza başka amaçlara hizmet eden bir araç olarak görülmüsstür. Bu bağlamda bu iki teori tarafından ortaya konmuş olan, ceza ve cezalandırmanın arasındaki ilişki, onların farklılıkları bakımından tartışılmaya çalışılmıştır.
\end{abstract}

Anahtar kelimeler: suç, ceza, cezalandırma, kefaret teorisi, faydacı teori

\section{Comparison Of Theory Of Atonement And Theory Of Utilitarian About Punishment}

\begin{abstract}
In this study, the obligation and necessity of the punishment with the expression of social reaction against the behaviors that disrupt the social order is emphasized. In the legal system, the name of this behavior appeared as a crime. Primarily, the aim of the punishment was tried to be determined and two of the theories accepted were considered when punishment was applied. In theory of atonement, which is one of these theories, punishment itself is seen as an aim, whereas in the theory of utilitarian theory, punishment is seen as a means to serve other purposes. In this context, the relationship between punishment and retribution, which was put forward by these two theories, was tried to be discussed in terms of their differences.
\end{abstract}

Keywords: prime, retribution, punishment, atonement theory, utilitarian theory

${ }^{1}$ Yüksek lisans öğrencisi, Kocaeli Üniversitesi, Sosyal Bilimler Üniversitesi, Felsefe Anabilim Dal1, burcuenis34@gmail.com 


\section{Giriş}

İnsanlık tarihinin her döneminde cezaya rastlanır. Cezanın gerekliliği ve zorunluluğu da toplum halinde yaşama mecburiyetinden doğar. Toplum düzenini bozan davranışlara karşı sosyal tepki ifadesi taşıyan ceza, hukuk düzenini sağlamada ve devletin devamında vazgeçilmez bir olgudur. Ancak amacı belirlenebildiği zaman ceza, toplum iradesini ortaya koymuş olur. Fakat cezalandırmanın amacının belirlenmesine ilişkin tek bir teori yoktur. Ceza hukuki teorilerine baktığımız zaman bunları genel olarak, cezayı mutlak bir amaç olarak suç sayılan eylem için verilmiş bir karşılık, bir kefaret gören mutlak ceza veya adalet teorisi, cezayı suçları önleyici ve suçluları ıslah edici bir yöntem olarak gören faydacı yaklaşım ve her iki yaklaşımı da birlikte değerlendiren karma yaklaşım olarak özetleyebiliriz. ${ }^{2} \mathrm{Bu}$ yaklaşımları göz önünde bulundurarak Türk Ceza Kanunun 1.maddesine baktığımızda ceza kanununun amacı; kişi hak ve özgürlüklerini, kamu düzen ve güvenliğini, hukuk devletini, kamu sağlığını ve çevreyi, toplum barışını korumak, suç işlenmesini önlemektir. Kanunda, bu amacın gerçekleştirilmesi için ceza sorumluluğunun temel esasları ile suçlar, ceza ve güvenlik tedbirlerinin türleri düzenlenmiştir, hükmüyle karşılaşırız. (5237 numaralı kanun, 26.09.2004) Burada cezanın bir ödetme, bir kefaret olduğu veya ıslah edici amacının olduğu yer almamış olsa bile, Türk Ceza Kanununu bir bütün olarak değerlendirdiğimizde bu amaçların da bulunduğunu inkâr edemeyiz. Yani karma yaklaşım hariç, diğer iki teoriden yalnızca birinin ceza hukukunda cezalandırmanın amacı olduğu görülmez. Fakat bu çalışmayla bir ödetme, kefaret olarak cezalandırma ve önleme ile 1slah etme teorilerini içinde barındıran fayda olarak cezalandırma teorileri ortaya konulup, bunlardan birinin -kefaret olarak cezalandırmanın- ceza hukukunun amacını belirlemede çok daha adil olduğu ve insanı yabana atmadığı ortaya konulmaya çalışılacaktır. Kefaret olarak cezalandırma ile ilgili olarak Helbert Morris'in cezalandırma anlayışına, fayda olarak cezalandırma ile ilgili olarak Bentham'ın cezalandırma anlayışına değinilmeye çalışılacaktır.

\section{I-Cezalandırmada Faydacı Teori ve Kefaret Teorisi}

Faydacı ceza teorisi, cezalandırmanın kendisini bir amaç değil araç olarak görür. Dolayısıyla cezanın pratikte fayda sağlaması halinde başvurulması gereken bir şey olduğu savunulur. Bu teoriye göre ceza, uygulamada iyi sonuçlar doğurursa izin verilebilir bir şeydir. Dolayısıyla faydacı teori cezayı sonuçları bakımından meşrulaştırmaya çalışmıştır. Kefaret olarak cezalandırma anlayışına baktığımızda ise faydacı yaklaşımın aksine cezalandırmanın kendisi bizatihi bir amaçtır. Bu yaklaşıma göre suçlu işlediği suçun karşılığını geri ödemek zorundadır ve bu anlamda ceza suçlunun acı çekmesi için verilir. Böylece suçlunun yaptığı kötülüğün karşılığını alması sağlanacak ve ihlal edilen adalet ilkesinin öcü alınacaktır. ${ }^{3}$ Dolayısıyla suçlunun eyleminin ortaya çıkardığı haksızlığın ödenmesi sağlanıp moral denge onarılacaktır. Öte yandan faydacı teorinin cezalandırma amacı geçmişle değil

\footnotetext{
${ }^{2}$ Doç. Dr. Sururi Aktaş, Cezalandırmanın Amacı Üzerine, (EÜHFD,C.XIII,S.1-2,2009), s.1
}

${ }^{3}$ A.g.e., s.16 
gelecekle ilgilidir. $\mathrm{Bu}$ anlamda söylenmesi gereken en önemli şey de cezaların suçları önleyici (caydırıcılık) bir amaç taşımasıdır. Önleme ise genel önleme ve özel önleme diye ikiye ayrılır. Cezaların genel önleme amacı, maliyet-fayda hesabı yaparak gelecekte insanların suç işlemelerini engellemeyi amaçlarken; özel önlemenin amacı ise, suçluyu yeniden suç işlemekten alıkoymak, suçluyu toplumdan soyutlayarak toplumu korumak ve suçluyu islah etmektir. ${ }^{4}$ Sonuç olarak bütün bu amaçlar, geleceğe dönük olarak bir fayda düşüncesini içerirken, cezayı bir kefaret olarak gören teori, cezalandırmayı gelecekle ilgili değil, geçmişle ilgili bir işlem olarak görür. Başka bir anlatımla cezalandırmanın meşruluğu geçmişle ilişkilendirilir.

\section{II-Bentham'ın Faydacı Ceza Teorisi ile Morris'in Kefaretçi Ceza Teorisi}

Bentham'a göre “'yasa koyucunun konusu, kamunun mutluluğu; yasamanın muhakeme ilkesi ise, genel fayda olmalıdır." ${ }^{5}$ Dolayısıyla toplumsal mutluluğu arttırmak için fayda ilkesinin ne olduğunu ortaya koymak gerekir. Bu noktada öncelikle Bentham'ın ahlak felsefesini ve dolayısıyla erdemi de fayda/yarar prensibi açısından tanımlamaya çalıştığını söyleriz. Çünkü doğa insanı haz ve 1stırap duygularının etkisi altına alır ve insana bu duygulardan bağımsız bir eylemde bulunma hakkı tanımaz. Bentham ahlak tanımlamasını insan doğası üzerine temellendirmiştir ve ona göre insan doğasına egemen olan iki ilke vardır. Yani fayda prensibi her şeyi bu iki duyguya bağımlı kılar. Bunlar da haz ve 1stıraptır. Bu iki ilke insan davranışlarını yöneten en önemli motivedir. Fayda, bir kötülükten korunmak eğilimini ya da bir iyilik sağlamak özelliğini dile getirir ve iyilik de haz veya haz sebebidir. "Faydanın mantığı da, bütün yargılama işlemlerinde, başka hiçbir fikri katmadan, haz ve acı karşılaştırması, hesabı yapmaya dayanır." ${ }^{\prime 6}$ Böylece Bentham etik bakımdan doğru olanın haz ve mutluluğu arttırmak olduğu sonucuna varır. Bu tutumunu siyaset ve hukuk felsefesi içinde de korur. Ona göre birey ve toplumun faydasının arttırılması gerekir. Bu amaç, Bentham'ın siyaset ve hukuk felsefesinde, en büyük sayının en büyük mutluluğu olarak klişeleşmiştir. ${ }^{7}$ Bu doğrultuda faydacılık üzerine dayanan pozitivist bir hukuk felsefesini ortaya koyan Bentham'a göre pozitif hukukun fayda ilkesi açısından değerlendirilmesi gerekir. Bu düşünceler doğrultusunda bir ahlak kuralı kendiliğinden iyi ya da kötü olamaz. Dolayısıyla ahlak kuralları gibi hukuk kurallarının da iyi ya da kötü olup olmadığı pratikteki faydalarına göre ölçülür. Bu anlamda Bentham, ceza hukukunda eylemlerin kendiliğinden kötü olanlar ve yasa tarafından yasaklandığı için kötü olanlar şeklinde ayrılmasına karşıdır. Eylemin iyiliği ya da kötülüğü, sonuçlarına göre ölçülecektir. Bentham'ın bu faydacı teorisi, cezalandırmayı bir kefaret olarak gören anlayış ile uyuşmaz. Çünkü bu anlayışa göre, bizzat eylemlerin kendileri iyi veya kötüdür. Dolayısıyla doğal hukukta hiçbir fayda gözetmeksizin, ahlak kurallarının çiğnenmesi bir kötülük olarak algılanır. Morris'de bunu şöyle ifade eder:

\footnotetext{
${ }^{4}$ A.g.e., s. 2

5 Jeremy Bentham, Yasamanın İlkeleri, çev. Barkın Asal (İstanbul:On İki Levha Yayıncılık,2011), s.1

${ }^{6}$ A.g.e., s. 3

${ }^{7}$ Doç. Dr. Sururi Aktaş, Cezalandırmanın Amacı Üzerine, s. 8
} 
Amacım, haklar üzerine, bazıları tarafından sadece yanlış değil aynı zamanda abes görünecek, 4 hipotez üzerine tartışmak: ilki ceza almaya hakkımız olması; ikincisi, bu hakkın, kişi olarak görülme temel hakkımızdan gelmesi; üçüncüsü bu temel hakkın, doğal, dışlanamaz ve kesin olması; ve dördüncüsü de, bu hakkın reddinin tüm ahlaki hak ve görevlerin reddine yol açmasıdır. ${ }^{8}$

Açıktır ki Morris'e göre cezanın ahlaki ölçütü hak etmedir. Onun ceza sisteminde, kişilerin bireysel özgürlükleri maksimize edilerek insanların etkisinden bağımsız bir yaşam alanı yaratılması hedeflenmiştir. Morris’e göre 'temel kurallara bağlı cezalarımız, kişinin seçim yapma özgürlüğünü baz alarak, cezayı bireyin kuralı ihlal etmeyi isteyerek seçmesi haline bağlamıştır ve bu şekilde kişinin cezalandırmayı kendisinin seçtiği fikri savunulabilir." ${ }^{, 9}$ Bentham'ın faydacı teorisine baktığımızda ise bu değişerek, kişinin özgür iradesiyle seçim yapıp yapmaması, toplumun vereceği tepkiyi belirleyen bir faktör olmaktan çıkar. Morris'in teorisinde, var olan ve kişinin istem dişı olarak yaptığı eylemlerden dolayı ceza almasını engelleyici tüm mekanizmalar, faydacı teoride anlamsızlaşır. Zira faydacı teoriye göre verilecek ceza, kişinin yaptıklarının kendi seçimi olup olmamasından bağımsızdır. Dolayısıyla burada hak etme kavramına yer yoktur ve adalet fayda-yarar sağlayıcı bir araç haline gelmiştir. Kefaret teorisi insanı temele alarak ve ahlaki kuralları gözeterek, cezalandırmayı hafiflettirici nedenleri göz önünde bulundururken faydacı teori için ise sadece ceza ile ondan sağlayacağı yarar önemlidir. Bu yüzden faydacı teori ahlaki değerleri ve insan vicdanını umursamaz. Dolayısıyla sadece fayda gözeten bir yasa adil olmaktan ve bağlayıcı olmaktan çıkarak sadece uzlaştırıcı bir araç haline dönüşür.

\section{III-Bentham'da ve Morris'te Cezanın Temellendirilmesi}

Bentham açısından "bütün yasaların ortak genel amacı, toplumdaki toplam mutluluğu artırmaktır veya artırmak olmalıdır; ve dolayısıyla ilk elde bu mutluluğu azaltacak her şeyi mümkün olduğunca ortadan kaldırmaktır: diğer bir deyişle, yanlış edimi dışlamaktır." ${ }^{10}$ Ancak Bentham açısından ceza da bir kötülüktür. Çünkü tüm cezalar, kendi içinde uygunuz hareketlerdir ve kötülük yapmayı gerektirir. "Faydacılık prensibine göre -bunu kabul ediyorsak eğer- ceza, sadece kendinden daha büyük bir kötülüğü dışlaması durumunda kabul edilebilir."11 Bu anlamda Bentham, cezalandırmanın amacını ortaya koymak için özel önleme ve genel önleme kavramlarını anlatır. Fakat ona göre cezalandırmanın temel amacı genel önlemedir. Bunu şu sözlerle ortaya koyar:

Genel önleme, cezalandırmanın temel meşruluk temeli olduğu gibi, temel amacı da olmalıdır. Eğer bir suçu, benzeri asla gerçekleşmeyen tecrit edilmiş bir eylem olarak mülahaza edebilseydik

\footnotetext{
${ }^{8}$ Frederick Schauer \& Walter Sinnott-Armstrong, The Philosophy of Law-Classic and Contemporary Roadings with Commentary, "A Retributive Theory of Punishment \& Herbert Morris", (Harcourt Brace Collage Publishers:1995), s.853

${ }^{9}$ A.g.e., s.859

${ }^{10}$ Jeremy Bentham, Ahlak ve Yasama Illkelerine Giriş, çev. Prof. Dr. Aysel Doğan (AÜHDF,C.57 Sa.4,2008) s.388

${ }^{11}$ Michael J.Gorr \& Sterling Harwood, Crime and Punishment-Philosophic Explorations, (Jones and Bartlett Publishing,1995), s.288
} 
cezalandırma faydasız olacaktı. $\mathrm{Bu}$, sadece bir kötülüğün diğerine eklenmesi olacaktı. Fakat biz, cezalandırılmamış bir suçun, sadece aynı fail için değil ve fakat aynı zamanda suç işleme güdü ve firsatlarına sahip olanlara da suç işleme yolunu açtığını düşündüğümüz zaman, bir kişiye verilen cezanın herkes için bir güvenlik kaynağı olacağını anlarız. ${ }^{12}$

Özel önleme bakımından ise cezanın üç amacı vardır. Bunlar, suçlunun suç işleme yeteneğini ortadan kaldırma, suçluyu 1slah etme ve gelecekte suç işlememesi için gözdağı vermedir. ${ }^{13}$ Bunlar suçlu açısından cezalandırmanın felsefesini oluşturur. Bentham'ın, cezalandırmayı bu şekilde haklılaştırması, cezayı bir amaç olarak değil bir araç olarak görmesinden kaynaklanır. Bu şekilde cezanın kendisinden daha büyük kötülükler engellenerek fayda prensibi gözetilmiş olacaktır. Açıç̧a görülür ki Bentham'ın bu yaklaşımı, cezayı bir kefaret ve kötülüğe karşı muhakkak verilmesi gereken bir karşılık olarak değerlendiren teoriyle uyuşmamaktadır. Çünkü Morris’e göre “ceza bir kişinin, suçlu bulunması ile haklılaştırılan ve genel olarak yanlış olduğu kabul edilen bir davranışta bulunması nedeniyle kendisine uygulanan bir yaptırımdır." ${ }^{14} \mathrm{Bu}$ yüzden içinde kızma ve kin barındırır çünkü suçlu, yapabilecek olmasına rağmen başkaları gibi kendini sınırlamamıştır. Bu anlayışın aksine fayda prensibini gözetenler suçluların suç işleme yeteneğini ortadan kaldırmak için terapi yöntemini önerirler. Bu yöntemde terapi hatalı bir insana verilen tepki değildir. "Kişiye yaptığı bir yanlışlık nedeniyle değil, o yanlışı yapmasına sebep olan bir hastalığı nedeniyle terapi verilir." ${ }^{15}$ Eğer bu marazi duruma sahip değil ise terapinin bir anlamı kalmaz. Bu nedenle kefarete dayalı cezalandırma anlayışı geçmişle ilgilenirken, terapi ise fayda gözettiği için geleceğe dönüktür. "Terapi, normalde kişinin yaşadıklarından ötürü şefkatle bağdaştırılırken, ceza, hatalı olarak yaptıklarından ötürü kin ile bağdaşır." 16 Bunun yanı sıra terapiyle, cezalandırmada olduğunun aksine, suçluyu iyi bir şeyden mahrum bırakmak değil, iyileşebileceği umuduyla hastalığını tedavi etmeye çalış1ır. Dolayısıyla suçluya karşı yapılan bu iyilik, onun tarafından hak edilmiş bir ödül değildir. Yalnızca bir birey olarak acı çekme kapasitesi nedeniyle sempatimizi kazandığı için iyilik gösterdiğimiz biridir. Oysa kefaret anlayışına dayalı ceza, kişinin haksız elde ettiği avantajı silerek fayda sorumluluk dağılımı dengesini sağlamaya yöneliktir. "Bu nedenle cezanın içeriği 'kişinin topluma borcunu ödemesi olarak görülür ve cezalandırma için kişiden değerli kabul edilen bir şey alınır." ${ }^{17}$ Bu borçlanma bakışı, aynı zamanda borcun affedilmesi yoluyla suçun cezalandırılmama durumunu da mümkün kılar. Bentham'ın faydacı teorisine dönüp baktığımızda ise bu tarz bir topluma borç ödeme ya da borcun affedilmesi kavramlarına yer verilmediği açıktır. Çünkü faydacı anlayışa göre ceza, bir kişinin cezalandırılmayı

\footnotetext{
12 Doç. Dr. Sururi Aktaş, Cezalandırmanın Amacı Üzerine, (EÜHFD,C.XIII,S.1-2,2009), s.9

${ }^{13}$ A.g.e., ss.9-10

${ }^{14}$ Frederick Schauer \& Walter Sinnott-Armstrong, The Philosophy of Law-Classic and Contemporary Roadings with Commentary, "A Retributive Theory of Punishment \& Herbert Morris", (Harcourt Brace Collage Publishers:1995), s.857

${ }^{15}$ A.g.e., s. 857

${ }^{16}$ A.g.e., s.857

${ }^{17}$ A.g.e., s.857
} 
hak edip etmemesine bakılarak değil, fayda-yarar sağlayıp sağlayamayacağı gözetilerek verilir ve hak etme kavramı olmadığından ötürü affetme kavramına da yer yoktur.

\section{IV-Cezalandırmanın Uygun Olmadığı Durumlar Karşısında Geleneksel Adalet Anlayışı}

Bentham'a göre aşağıdaki durumlarda ceza uygulanmaması gerektiği açıktır:

1) Temelsiz olduğu noktada; önleyecek bir kötülük olmadığında; yapılmış olan eylem, genelinde kötü olmadığında.

2) Etkisiz olduğu noktada; kötülüğü engelleme anlamında işe yaramayacaksa.

3) Karsız olduğu noktada; cezanın kendi yaratacağı kötülük, yapılan eylemden daha büyük olacak ise.

4) Gereksiz olduğu noktada; yapılan kötülük, ceza olmaksızın engellenebilecek ya da kendisi ortadan kalkacak ise; öyle ki daha az maliyetli bir şekilde. ${ }^{18}$

Bentham'a göre cezalandırmanın temelsiz olması durumunda, cezalandırılmak istenilen davranış herhangi bir kimseye kötülük oluşturmuyordur. Ayrıca eylem kötülük oluşturmuş olsa bile eğer zarar gören ya da etkilenen kişinin rızası varsa, bu durumda da ceza vermek temelsizdir. Bentham'a göre “'yapılan kötülük gölgede kaldığı noktada; her ne kadar yapılan eylem bir kötülüğe yol açtıysa da, aynı eylem, başka, daha büyük değerde bir iyilik üretiyorsa cezalandırma temelsizdir." 19 Örneğin; tecavüze uğrayacak birini kurtarmak için, saldırgana elindeki sopayla vurup onu etkisiz hale getiren birini cezalandırmak temelsizdir. Bentham son olarak da, yapılan kötü harekete uygun bir tazminatın geleceği garantisi varsa, cezalandırmanın temelsiz olduğunu söyler. Burada insan hayatının, parayla ölçülebilecek kadar değersiz görüldüğü açıktır. Zira Bentham ahlak kurallarına, fayda sağlama durumunu hesaba katarak, iyilik ya da kötülük atfeder. Oysa kefaretçi teori, geleneksel adalet anlayışı, insanı temele alarak, ona değer atfederek ve ahlaki kuralları gözeterek bir cezalandırma anlayışı sergiler. Bu temelde ahlak kuralları da şarta bağlı olamayacağı için, cezalandırma faydacılık açısından temellendirilmemeli veya hafifletilmemelidir.

Cezalandırmanın etkisiz olduğu durumlara geldiğimiz zaman, Benthama göre “ceza kanunu eylem olup bittikten sonra çıkarıldıysa cezalandırma etkisizdir." ${ }^{20} \mathrm{Bu}$ nedenle, daha önce suç olarak belirtilmeyen bir davranış gerçekleştirildikten sonra, bunu suç haline getiren bir kanun çıkarıp ceza vermek ya da cezanın miktarını arttırmak anlamsızdır. Bentham'a göre "ceza hükmü, her ne kadar çıkarılmış olsa da uygulanması hedeflenen kişinin dikkatine tebliğ edilmediyse cezalandırmak etkisizdir." 21 Öte yandan ceza yasaları yazılırken, bunlar tüm ilgililerin (suç işleme potansiyeli olanlar) cezalandırılabileceği (dokunulmaz olmaması) bir şekilde yazılmalıdır. Eğer ceza hükmü,

\footnotetext{
${ }^{18}$ Michael J.Gorr \& Sterling Harwood, Crime and Punishment-Philosophic Explorations, (Jones and Bartlett Publishing,1995), ss.288-289

${ }^{19}$ A.g.e., s. 289

${ }^{20}$ A.g.e., s. 289

${ }^{21}$ A.g.e., s. 289
} 
şahsa tebliğ edilmiş olsa bile, kişi üzerinde suçu işlememe yönünde hiçbir etkisi olamayacaksa da cezalandırma etkisizdir. Örneğin; çocuk yaşta olan biri kötülük düşünmeye uzaktır ki kanun tarafından belirtilen yaptırımlar, davranışlarını etkileyemez. Öte yandan "bir sebepten dolayı kişi mantıklı karar verme yetisini yitirmiş ise Bentham bu duruma delilik der.",22 Örneğin; kişi madde etkisi altındaysa, içki, uyuşturucu ya da bir başka ilacın etkisindeyse geçici olarak bir delilik durumunda olabilir. $\mathrm{Bu}$ yüzden ceza ehliyeti olmayanların cezalandırılması ile irade dışı yapılan suç eylemlerinin cezalandırılması, cezadan beklenen yararı sağlayamayacağı için etkisizdir.

Böylece Bentham'ın yararcılığı açıkça ortaya çıkmaktadır. Çünkü ceza ehliyeti olmayanların cezalandırılmaması gerektiği düşüncesine, moral değerler veya adalet ideali açısından değil ancak cezadan beklenen amacın gerçekleşmeyeceği düşüncesiyle ulaşmaktadır. Öte yandan onun fayda düşüncesiyle baktığımızda cezalandırma, eğer diğer akıl hastaları üzerindeki amacını gerçekleştiriyor olsaydı, ceza ehliyeti olmayan bir akıl hastasını cezalandırmak da yararlı olurdu. Oysa bu, Morris'in benimsediği kefaretçi cezalandırma anlayışına aykırıdır. Çünkü akli dengesi yerinde olmayanları, sonuçta yarar sağlayacak olsa bile, işledikleri suçlardan dolayı cezalandırmak, geleneksel adalet düşüncesiyle bağdaşmaz. Bentham’a göre “kasıtsızlık durumunda; kişi eylemi gerçekleştirmek niyetinde değil ise ve bu nedenle daha sonrasında gerçekleştireceği eyleme başlamak üzere olduğunun farkında değil ise kişinin cezalandırılması yararsızdır." ${ }^{23}$ Kasıtsız bir hareket yapan kimse cezalandırılarak, yaptığı hareketi ileride tekrarlaması engellenemez. Kişi kasıtlı bir iş yapmış olmasına rağmen yaptığının tüm sonuçlarını kestiremediği ya da düşünemediği için, ortaya farklı sonuçlar çıkmış olabilir. Bu yüzden burada da cezalandırmak etkisizdir çünkü kişi yaptığı davranışın nasıl sonuçlar doğuracağını bilmeden bu şekilde davranmıştır. Son olarak da kişi kötülüğü yaparken aslında çok daha büyük bir iyi sonuç elde etmeye çalışıyor olabilir. Örneğin; saldırıya uğrayan birine yardım etmek için, saldırgana vuran bir kimse, sonradan, aslında o kişilerin kendi aralarında oyun oynadıklarını öğrenir. Böylece iyilik yaptığını düşünen kişi, suç işlemiş konuma düşer.

Cezanın kârsız olması durumuna geldiğimizde ise, Bentham suç ile ceza arasındaki orantısızlıktan söz eder. Bu durumu şöyle açıklar: "Bir elde gerçekleşen ihlalin doğası, diğerinde cezanınki varken ve normal şartlar altında bunları karşılaştırdığımızda, cezanın kötülüğü daha büyük olarak görülüyorsa bu durumda cezanın götürüsü getirisinden daha çok olacağı için cezalandırmak karsızdir.',24

Son olarak cezanın gereksiz olduğu duruma geldiğimizde Bentham, fayda-maliyet hesabını göz önünde bulundurur ve cezalandırmanın amacı ucuz bir maliyetle etkili bir biçimde sağlanabilecekse cezalandırmanın gereksiz olduğunu söyler. Onun deyimiyle: "Eğer suçun bir daha

\footnotetext{
22 A.g.e., s. 289

${ }^{23}$ A.g.e., s. 289

${ }^{24}$ A.g.e., s. 290
} 
işlenmemesini daha basit yöntemlerle -örneğin eğitim ile ya da korkutarak- sağlayabileceksek cezalandırmak gereksizdir.",25

Açıkça görülür ki Bentham'ın cezalandırma yaklaşımı, bir fayda-maliyet hesabına dayanmaktadır. Bu anlayış, cezaları hak edildiği için değil, hem suç işleyenler ve hem de suçtan zarar görenlerin yararları açısından meşrulaştırmaya çalışmaktadır. Bu yüzden bu yaklaşım, Morris'in kefaretçi cezalandırma anlayışıyla dolayısıyla geleneksel doğal hukuk düşüncesiyle hem de semavî dinlerin ahlak anlayışıyla uyuşmamaktadır. Çünkü geleneksel hukuk anlayışında da semavi dinlerde de kötülük ve iyilik, yalnızca fayda açısından değerlendirilmez.

\section{V-Bentham ve Morris'in Ceza Teorisinde Suç ile Ceza Arasındaki Orantı}

Bentham suç ile ceza arasındaki oran konusuna gelindiğinde birçok kural saymaktadır. $\mathrm{Bu}$ kurallardan en önemlilerine bakmak istersek, bunlar;

“Cezanın değeri hiçbir durumda, suçun getirisi tarafından gölgede bırakılacak kadar küçük olmamalıdır.'”26 Yani cezalandırmanın kötülüğü, suçun suçluya sağladığı faydadan büyük olmalıdır. “ “ İki suç arasında seçim yapılması gerektiği durumlarda, büyük suçun cezasının küçüğü seçmeye teşvik edecek kadar büyük olması gerekir." 27 Örneğin; adam öldürmeye verilen ceza, adam yaralamaya verilen cezadan çok daha büyük olmalıdır. "Ceza, uygulanacağ 1 kesinliğinin az olduğu oranda büyütülebilir." ${ }^{28}$ Ya da ceza az olsa bile, eğer cezalandırma kesinse, bir kimse o suçu işlemeyi göze almaz. Örneğin; yakalanma ihtimali az olan bir suç işlenecekse onun cezasını büyük tutabilir ki, ufak ihtimalle de olsa suçlunun yakalanmaktan korkulması sağlanabilsin. Eğer yakalanma ihtimali çok büyük olan bir suç işlenmişse de ceza düşük tutulmalıdır. Morris ise Bentham'ın aksine, cezalandırmanın ortaya koyduğu kötülüğün, suçun suçluya sağladığı avantajdan büyük olması gerektiğini düşünmez. Morris’e göre “cezalandırmada, suç işleyenin elde ettiği avantajla -kısmen elde edilen fayda ve kısmen de bu faydayı elde ederken içinde bulunduğu ruh hali göze alınarak- uygulanan ceza arasında bir denge olmasına çalışılır." 29 Böylece zalim ve sıra dışı cezalar üzerinde sınırlama getirilerek orantısız acı çektirilmesinin önüne geçilir. Bentham'ın fayda anlayışını içeren terapi girişiminde ise orantısallığın mantığı yoktur. "Tedavi doğası gereği faydalı kabul edildiğinden, acılı bile olsa, uygulanırken cezaya oranla daha rahat davranılabilir." ${ }^{30}$ Daha da ötesinde tedaviye itiraz, hayatını kurtarmak için ayağını kesmek zorunda kaldığınız bir hastanın şikâyeti gibi görülüp göz ardı edilebilir. Zira tedavi hastalıktan daha kötü kavramı terapi dünyasında mevcuttur. Morris'in cezalandırma sistemindeki kurallar, başkalarının haklarına doğrudan müdahale ya da başkalarını riske

\footnotetext{
${ }^{25}$ A.g.e., s. 291

${ }^{26}$ A.g.e., s. 292

${ }^{27}$ A.g.e.i s. 292

${ }^{28}$ A.g.e., s. 293

${ }^{29}$ Frederick Schauer \& Walter Sinnott-Armstrong, The Philosophy of Law-Classic and Contemporary Roadings with Commentary, "A Retributive Theory of Punishment \& Herbert Morris", s.858

${ }^{30}$ A.g.e., s. 858
} 
sokan durumlara sebep olan davranışları düzenleyecek şekildedir. Oysa "tamamen tedavi edici ve önleyici bir ideolojiyle motive olan bir sistemde ise, semptomların kendini çevreye zarar verici şekilde göstermesini beklemeye gerek yoktur." ${ }^{31}$ Cezalandırma sisteminde ise kişi bazı haklarından mahrum edildiği için suçun kesinleşmesinin beklenilmesi doğaldır. Terapi sisteminde ise faydalı bir şey olduğu için, beklenilmesi için bir sebep yoktur. Morris’e göre “tedavi mantı̆̆ı, bizi, kaçınılmaz olarak, kişinin iradesi dışında değişikliğe uğratılmasına itecektir." ${ }^{32} \mathrm{Bu}$ durumun kötülüğü en can alıcı biçimde, hareketleri hastalık olarak görülen kişinin bu durumunu hastalık olarak kabul etmediği hallerde görülecektir. "Kişi, kendisinin yaptıklarını "doğru” kabul etmekte ancak kişinin normal anlayışı, terapi dünyasının normal anlayışı ile uyuşmamaktadır." 33 Böyle bir durumda, kişi kendi seçtiği hareketleri için tedavi edilmeye başlanıldığında, onu normal davranmaktan alıkoyan bir durum giderilmeyip, birey, o anki terapi dünyasının normal kabul ettiği şekilde davranacak biçimde değiştirilmeye çalışılır. Dolayısıyla kişi ve değer yargıları değiştirilerek şahsın ahlaki durumuna, onun mantık ve seçimlerine saygı duyulmaz. Bu durumda kişi şartlanması gereken bir hayvandan farksızdır. Morris, tedavinin insanı getirdiği bu aşamada şu sözleri söyler: "Sanıyorum, hepimiz, zorla, olmadığı bir kişiye dönüşmektense ölmeyi tercih eden bir insanı anlayabilir ve sempati duyabiliriz." ${ }^{34} \mathrm{Bu}$ durumu örneklendirmek istersek: Dünyamızın distopik bir versiyonunda geçen Anthony Burgess'in Otomatik Portakal (Clockwork Orange) romanında, hikayenin anti-kahramanı Alex, bir grup arkadaşı ile birlikte cinayet, vandalizm, tecavüz gibi suçları göz kırpmadan işler. Sonunda yakalanan Alex, hapishaneye atılır ve cezasını çekmeye başlar. Buraya kadar geleneksel adalet anlayışı, cezalandırmayı bir kefaret olarak görüp, suçluya suçundan dolayı ceza vererek, onun topluma olan borcunu ödemesini gözetir. Ancak bir süre sonra cezalandırmanın yeterli olmadığına inanan devlet, şiddeti ve anti-sosyal davranışları kimyasallar ve hipnoz uygulamaları ile tedavi edecek bir yöntem geliştirir. İşte bu noktada faydacılığın benimsediği terapi-tedavi uygulamasına geçilmiştir. Kendi bilincinin yıkılmazlığına inanan Alex, bu tedaviyi kabul eder ve acılı bir sürecin sonunda gerçekten şiddet ve cinsellik eylemlerinde bulunamaz hale gelir. Ne zaman şiddet uygulamaya kalksa (içindeki istek azalmamıştır) vücudu tepki verir ve hastalanır, ayakta duramaz hale gelir. Kendisi olmaktan o kadar uzaklaşmıştır ki, insan olmaktan ziyade kendini içinde bir kanun mekanizması haline gelmiştir. Öyle ki, artık ismini Alex değil A Lex (Latince "kanun" demek) olarak telaffuz etmektedir. Hikayenin başında kötücül ama müzikten, güzel sanatlardan zevk alan Alex artık bilinçsiz bir varlığa dönüşür. Sonunda da tıpk1 Morris'in düşündüğü gibi, olmadığ1 bir insana dönüştüğünü hissedince, içinde bulunduğu duruma dayanamayarak intihar girişiminde bulunur. Görüldüğü üzere terapi süreci hakkında yukarıda bahsedilmiş olunan her şey birebir olarak bu romanda gösterilmiştir. Son olarak olması gereken şeyi

\footnotetext{
${ }^{31}$ A.g.e., s. 858

${ }^{32}$ A.g.e., s. 860

${ }^{33}$ A.g.e., s. 860

${ }^{34}$ A.g.e., s. 860
} 
yazarın kendi ifadesiyle söylemek istersek; insanın kendi özgür iradesiyle kötü olması, zorla iyiymiş gibi davranmasından iyidir.

\section{Sonuç}

Cezanın gerekliliği ve zorunluluğu toplum halinde yaşama mecburiyetinden doğmuştur. Toplum düzenini bozan davranışlara karşı sosyal tepki ifadesi taşıyan ceza, hukuk düzenini sağlamada ve devletin devamında vazgeçilmez bir olgu olmuştur. Bu yüzden öncelikle cezalandırılmanın amacı belirlenmeye çalışılmıştır. Cezalandırmanın amacı bakımından kabul edilen temel teorilerden birisi kefareti esas alan ceza teorisiyken diğeri ise faydayı esas alan ceza teorisidir. Kefaret teorisinde cezanın kendisi bizatihi bir amaç olarak görülürken faydacı ceza teorisinde ise ceza başka amaçlara hizmet eden bir araç olarak görülmüştür. Faydacı teori için cezanın amaçları, suçların işlenmesini önlemek ve suçluların ıslahıdır. Bu anlamda faydacı teori, ceza hukukunda eylemlerin kendiliğinden kötü olanlar ve yasa tarafından yasaklandığı için kötü olanlar şeklinde ayrılmasına karşıdır. Eylemin iyiliği ya da kötülüğü, sonuçlarına göre ölçülecektir. Cezalandırmayı bir kefaret olarak gören anlayışa göre ise bizzat eylemlerin kendileri iyi veya kötüdür. Dolayısıyla doğal hukukta hiçbir fayda gözetmeksizin, ahlak kurallarının çiğnenmesi bir kötülük olarak algılanır. Fayda prensibini gözetenler suçluların suç işleme yeteneğini ortadan kaldırmak için terapi yöntemini önerirler. Dolayısıyla ceza, kişiden değerli olan bir şeyi almak ve işlediği suçtan ötürü topluma olan borcunu ödemek anlamı taşırken, terapiyle suçluya hak edilmemiş bir iyilik yapılmış olur. Görülür ki faydacı ceza teorisinde hak etme kavramına yer yoktur, dolayısıyla affetme kavramı da bu teoride yer bulamaz. Faydacı ceza teorisi cezalandırmanın ortaya koyduğu kötülüğün, suçun suçluya sağladığı avantajdan büyük olması gerektiğini düşünürken kefaretçi ceza teorisi ise cezalandırmada, suç işleyenin elde ettiği avantajla kısmen elde edilen fayda ve kısmen de bu faydayı elde ederken içinde bulunduğu ruh halini göze alarak- uygulanan ceza arasında bir denge kurar. Dolayısıyla faydacı ceza teorisinin anlayışına göre ortaya zalim, sıra dışı ve orantısız cezalar çıkar. Hatta kişi kaçınılmaz olarak, kendi iradesi dışında değişikliğe uğratılır. Faydacı teori bu anlayışıyla insanı ve ahlaki değerleri yabana atarak, yalnızca kendisinin sağlayacağı yararı düşünür. Bu yüzden cezalandırma hukukunda faydacı ölçütleri hesaba katmak, adalet kavramını zedeleyen sonuçlar doğur. Bundan dolayı cezalandırma felsefesinde, adalet prensibi esas alınmalı ve her kötülügün bir karşıllğının olması gerektiği düşüncesini temel alan kefaretçi düşünceden hareket edilmelidir. 


\section{Kaynakça}

AKTAŞ, Sururi. (2009). Erzincan Üniversitesi Hukuk Fakültesi Dergisi - Sayı:13, “Cezalandırmanın Amacı Üzerine"

BENTHAM, Jeremy. (2011). Yasamanin İlkeleri, İstanbul, On İki Levha Yayınc1lı

BENTHAM, Jeremy. (2008). Ankara Üniversitesi Hukuk Fakültesi Dergisi - Sayı:57, “Ahlak ve Yasama Ilkelerine Giriş"

GORR, J.Michael \& HARWOOD, Sterling. (1995). Crime and Punishment-Philosophic Explorations, SudburyABD, Jones and Bartlett Publishing

SCHAUER, Frederick. \& ARMSTRONG-SINNOTT, Walter. (1995). The Philosophy of Law-Classic and Contemporary Roadings with Commentary, Fort Wort-ABD, Harcourt Brace Collage Publishers 